\title{
Parâmetros de produção de leite de búfala fermentado por Lactobacillus casei
}

\author{
Cláudia Puerari Faria(1), Honório Domingos Benedet( ${ }^{(2)}$ e Jean-Louis Le Guerroue(3)
}

\begin{abstract}
(1)Universidade Federal do Pará, Centro de Ciências da Saúde, Dep. de Nutrição, Praça Camilo Salgado, oo 1, Umarizal, CEP $66050-060$ Belém, PA. E-mail: claudiapfaria@hotmail.com (2)Universidade Federal de Santa Catarina, Centro de Ciências Agrárias, Dep. de Ciência e Tecnologia de Alimentos, Rod. Admar Gonzaga, no 1346, Itacorubi, CEP 88034-001 Florianópolis, SC. E-mail: benedet@cca.ufsc.br (3)Universidade Católica de Brasília, SGAN 916, Módulo B, W5 Norte, Asa Norte, CEP 70790-160 Brasília, DF. E-mail: guerroue@pos.ucb.br
\end{abstract}

Resumo - O leite de búfala foi fermentado por Lactobacillus casei, com diferentes concentrações de açúcar e tempos de fermentação, e estocado durante 30 dias a 5 e $10^{\circ} \mathrm{C}$. Avaliaram-se a acidez, o pH e a viabilidade de $L$. casei nos diferentes tratamentos. O leite fermentado por 18 horas não apresentou os parâmetros requeridos para o produto, enquanto os fermentados por 22 e 24 horas apresentaram acidez e $\mathrm{pH}$ adequados. $\mathrm{O}$ tempo e a temperatura de estocagem influenciaram esses parâmetros. A viabilidade de $L$. casei inicial foi maior que

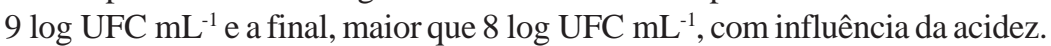

Termos para indexação: leite fermentado, probióticos, viabilidade.

\section{Production parameters of buffalo milk fermented by Lactobacillus casei}

\begin{abstract}
Buffalo milk fermented by Lactobacillus casei was elaborated with different sugar concentrations and fermentation times, and stored during 30 days at 5 and $10^{\circ} \mathrm{C}$. Acidity, $\mathrm{pH}$ and $L$. casei viability were evaluated in the different treatments. Milk fermented for 18 hours did not show adequate parameters for this product. Milk fermented for 22 and 24 hours presented adequate acidity and $\mathrm{pH}$. Storage time and temperature influenced these parameters. The $L$. casei initial viability was greater than $9 \log C F U ~ L^{-1}$ and the final was greater than $8 \log$ CFU mL $\mathrm{m}^{-1}$, with influence from acidity.
\end{abstract}

Index terms: fermented milk, buffalo milk, viability.

\section{Introdução}

A fermentação é um método de preservação largamente utilizado desde os primórdios da civilização, pela ausência de métodos de refrigeração ou pasteurização. Historicamente, o processo de fermentação envolvia a coagulação do leite por microrganismos presentes no meio, obtendo-se um produto final com características e propriedades físico-químicas diferentes da matériaprima (Alm, 1991).

As bactérias ácido-láticas utilizadas atualmente para a produção de leites fermentados pertencem principalmente aos gêneros Lactobacillus, Lactococcus, Streptococcus, Leuconostoc, Bifidobacterium, Propionibacterium, entre outros, e são assim denominadas por fermentarem açúcares, produzindo ácido lático como principal produto do metabolismo. Estas bactérias agem acidificando os produtos alimentares, impedindo o desenvolvimento de bactérias indesejáveis e aumentando o período de conservação dos produtos fermentados em relação à matéria-prima não fermentada (Piard et al., 1997).

Considera-se que alguns leites fermentados apresentam propriedades terapêuticas por serem elaborados com bactérias que incluem lactobacilos, bifidobactérias e estreptococos, cuja origem geralmente é o trato gastrointestinal humano e que apresentam, além dos efeitos bioquímicos e biológicos sobre os nutrientes do leite, efeitos fisiológicos e terapêuticos sobre o consumidor. Destas bactérias, em especial os lactobacilos e bifidobactérias possuem características que permitem sua classificação como probióticas (Alm, 1991).

Schrezenmeir \& Vrese (2001) propuseram a seguinte definição para probióticos: "Uma preparação ou um produto contendo microrganismos definidos e viáveis em número suficiente, que alteram a microbiota (por implantação ou colonização), em um compartimento do hospedeiro e que exercem efeitos benéficos à saúde deste hospedeiro". 
Entre os efeitos terapêuticos designados às bactérias probióticas, podem ser citados o alívio da intolerância à lactose, modulação do sistema imune, prevenção de distúrbios intestinais, além da possível ação na redução do colesterol sanguíneo e ações antitumorais (Saavedra, 2000; Vrese et al., 2001).

Os veículos existentes para carrear bactérias probióticas integram três grandes grupos: alimentos infantis, preparações farmacêuticas e produtos lácteos. Destes, o grupo mais representativo é o dos produtos lácteos, principalmente leites fermentados, iogurtes, sorvetes e queijos, nos quais utilizam-se freqüentemente culturas iniciadoras, como os lactobacilos, e como aditivo ou suplemento, as bifidobactérias (Gomes \& Malcata, 1999).

Os diferentes leites fermentados apresentam fases de produção similares, como padronização do conteúdo de gordura, aumento dos sólidos não gordurosos do leite, homogeneização, desaeração e tratamento térmico. Há, entretanto, aspectos técnicos importantes quando se deseja utilizar culturas probióticas, incluindo a necessidade de se determinar o tipo de cultura starter mais adequada, temperatura e tempo de incubação e taxa de inoculação (Tamine et al., 1995).

Entre os fatores que influenciam a viabilidade das bactérias probióticas no produto elaborado podem ser destacados o estado fisiológico dos organismos probióticos adicionados, as condições físicas de estocagem (tempo, temperatura), a composição química do produto no qual os microrganismos serão adicionados (acidez, conteúdo de carboidratos utilizáveis, fontes de nitrogênio, conteúdo mineral, atividade de água, conteúdo de oxigênio) e possíveis interações dos probióticos (bacteriocinas, antagonismo, sinergismo) com outras culturas starter (Heller, 2001).

Para determinar quando a fermentação deve ser finalizada, pode-se utilizar, como parâmetro, a porcentagem de ácido lático, sendo que o valor deve ser de no mínimo $0,60 \%$, para que haja inibição do crescimento de bactérias patogênicas ou deteriorantes que eventualmente estejam presentes no produto (Brasil, 2000).

Portanto, na produção de um alimento probiótico, é fundamental que a bactéria probiótica possa ser cultivada em escala industrial, sendo que o produto final deve ter vida média satisfatória, variando de 15 a 30 dias, e propriedades sensoriais - cor, aroma, sabor e textura aceitáveis, com os microrganismos presentes no produto viáveis e em número elevado ( $\left.>10^{6} \mathrm{UFC} \mathrm{mL}^{-1}\right)$ durante a vida-de-prateleira (Brasil, 2000; Trabulsi \& Sampaio, 2000).
Segundo Gomes \& Malcata (1999), a necessidade de manter um número elevado de microrganismos viáveis no produto final é decorrente da dose diária mínima recomendada, usualmente considerada de $10^{8}$ a $10^{9}$ células viáveis, obtidas pelo consumo de $100 \mathrm{~g}$ de produto com $10^{6}-10^{7}$ células viáveis por mL. Estes produtos devem ser consumidos regularmente para manter o efeito dos microrganismos na composição da microbiota intestinal.

A utilização do leite de búfala para elaborar produtos que tradicionalmente são derivados do leite de vaca é justificada quando se compara a qualidade nutricional e tecnológica destes. O leite de búfala, em relação ao de vaca, apresenta menor conteúdo de água e maior conteúdo de proteína, gordura e minerais (Food and Agriculture Organization, 1991; Nascimento \& Carvalho, 1993).

Produtos lácteos elaborados com leite bubalino, como muçarela e iogurte, apresentam melhor qualidade e rendimento que os produtos de leite bovino (rendimento de 39 e $40 \%$ a mais, respectivamente). Além disso, a elaboração de iogurte e outros leites fermentados, utilizando leite bovino, normalmente requer o aumento dos sólidos não gordurosos pela adição de substâncias espessantes para obter melhor viscosidade, textura e aparência no produto. Os mesmos produtos, elaborados a partir do leite de búfala, não necessitam dessas adições em virtude do maior conteúdo de sólidos totais e sólidos desengordurados. Portanto, o leite de búfala representa uma alternativa para o aproveitamento tecnológico (Hühn et al., 1986; Hühn et al., 1991; Benevides, 1998).

Este trabalho foi realizado com o objetivo de verificar, por meio da regressão linear múltipla, a influência das variáveis tempo e temperatura de estocagem e concentração de açúcar sobre a variação da acidez e do $\mathrm{pH}$ e verificar a viabilidade de $L$. casei, utilizando as variáveis: temperatura de estocagem, concentração de açúcar e acidez, visando a obter os melhores parâmetros para a tecnologia de produção de leite de búfala fermentado.

\section{Material e Métodos}

Na elaboração do leite de búfala fermentado por L. casei subsp. casei utilizou-se leite de búfala pasteurizado obtido de um laticínio em Ceilândia, DF, cuja composição centesimal, depois do desnate, era a seguinte: proteína, 4,35\%; carboidratos, 6,43\%; gordura, 0,10\%; e umidade, $88,65 \%$. 
Foi utilizada cultura comercial liofilizada de inoculação direta (Direct Vat Set - DVS) de L. casei subsp. casei (Texel Dried LBC 81). A cultura da bactéria foi diluída de forma asséptica na concentração recomendada pelo fabricante em leite em pó desnatado, reconstituído a 12\% e esterilizado (LDR 12\%), sendo posteriormente utilizado como inóculo para a fermentação do leite.

Foram utilizados $15 \mathrm{~L}$ de leite de búfala, desnatado em desnatadeira manual, visando a facilitar a fermentação, visto que as bactérias utilizadas como inóculo não possuíam atividade lipolítica. O leite foi dividido em três porções e adicionou-se açúcar nas concentrações de 10, 12 e 14\% (p/v). Depois de ser acondicionado em Erlenmeyer, realizou-se o tratamento térmico a $85^{\circ} \mathrm{C}$ por 15 minutos em banho-maria. Efetuou-se o resfriamento em banho de gelo, até alcançar $37^{\circ} \mathrm{C}$, e adicionaram-se $2,5 \%$ do inóculo de L. casei, com distribuição do leite inoculado em potes de plástico de $100 \mathrm{~mL}$, descartáveis e com tampa, que foram incubados a $37^{\circ} \mathrm{C}$. Foram realizadas três repetições desse delineamento em diferentes dias.

O leite foi fermentado por 18, 22 e 24 horas. Depois de cada tempo de fermentação, o produto foi estocado a 5 e $10^{\circ} \mathrm{C}$ por 30 dias. Para avaliar o produto, foram realizadas análises de $\mathrm{pH}$ e acidez em duplicata, semanalmente; contagem de $L$. casei, quinzenalmente, e análise de microrganismos de alteração.

Na análise da viabilidade de $L$. casei, utilizou-se o meio MRS (De Man, Rogosa e Sharpe), com incubação a $37^{\circ} \mathrm{C}$ por 72 horas, sob aerobiose. Depois da incubação, realizou-se a contagem das colônias típicas da bactéria (colônias cor creme, de diâmetro pequeno), com resultados expressos em UFC mL $\mathrm{mL}^{-1}$.

Em cada repetição, foram realizadas análises de $\mathrm{pH}$ e acidez (porcentagem de ácido lático) em duplicata, nos tempos 1 (18, 22 e 24 horas), 7, 14, 21 e 30 dias, utilizando-se a metodologia descrita pela Association of Official Analytical Chemists (1984).

A análise de microrganismos de alteração foi realizada no leite de búfala tratado termicamente, para verificar a presença de aeróbios mesófilos (contagem-padrão em placas). No leite fermentado foram realizadas as análises de coliformes a 45 e $35^{\circ} \mathrm{C}$, utilizando-se o método de Número Mais Provável (NMP $\mathrm{mL}^{-1}$ ) e análise de bolores e leveduras, por meio de plaqueamento em superfície. Os resultados foram confrontados com os critérios microbiológicos especificados na legislação brasileira (Vanderzant \& Splittstoesser, 1984; Brasil, 2000).
Os dados relativos à variação de acidez, pH e viabilidade das bactérias probióticas obtidos no experimento foram analisados por regressão linear múltipla, utilizando o programa Statistica 5.1 (Statsoft, 1998).

\section{Resultados e Discussão}

O leite de búfala utilizado para elaborar o leite fermentado por $L$. casei com diferentes concentrações de açúcar, tempos de fermentação e temperaturas de estocagem apresentou valores médios de: $\mathrm{pH}, 6,69 \pm 0,04$; e acidez, $0,18 \pm 0,02 \%$ de ácido lático. A contagem de aeróbios mesófilos de $10 \mathrm{UFC} \mathrm{mL}^{-1}$ (est.) indicou boa qualidade microbiológica da matéria-prima utilizada, em acordo com a legislação, e a efetividade do tratamento térmico (Brasil, 2000).

O produto apresentou-se de acordo com a legislação em relação à qualidade microbiológica para leite fermentado, e a viabilidade de $L$. casei no inóculo foi de $10^{11} \mathrm{UFC} \mathrm{mL}^{-1}$, adequada para a elaboração do produto. A caracterização das bactérias do inóculo e do leite fermentado resultou em bactérias gram positivas, em forma de bacilos e catalase negativas. Quando inoculadas em meio de cultura MRS e incubadas sob aerobiose, verificou-se o crescimento de colônias pequenas de cor cremeclara, caracterizando, portanto, qualidades fenotípicas e fisiológicas típicas de L. casei (Brasil, 2000).

O valor de acidez inicial desejável para leite fermentado é de, no mínimo, 0,6\% de ácido lático. O tempo de fermentação de 18 horas não foi suficiente para alcançar esse valor, portanto, neste caso, não foram realizadas as análises de regressão. O leite fermentado por 22 horas apresentou acidez inicial média variando entre $0,63 \pm 0,01$ e $0,67 \pm 0,02 \%$ de ácido lático e a fermentação por 24 horas resultou em valores médios de acidez inicial variando de $0,67 \pm 0,01$ a $0,71 \pm 0,01 \%$ de ácido lático, de acordo com as diferentes concentrações de açúcar e temperaturas de estocagem testadas.

Ao final do tempo de estocagem, aos 30 dias, a acidez apresentou valor médio de $0,87 \pm 0,11$ a $1,01 \pm 0,04$, para 22 horas de fermentação, e de $1,16 \pm 0,03$ a 1,26 $\pm 0,04$, para 24 horas de fermentação, sendo que este valor pode ser de no máximo $2 \%$ de ácido lático, de acordo com a legislação. Esses valores demonstram que L. casei apresenta pós-acidificação lenta, característica desejável para garantir viabilidade no produto durante a estocagem (Brasil, 2000).

Os valores médios iniciais de $\mathrm{pH}$ variaram de $5,35 \pm 0,03$ a 5,18 $\pm 0,13$, para 22 horas, e de 5,02 $\pm 0,06$ a 
$4,90 \pm 0,02$, para 24 horas de fermentação. Depois de 30 dias, o valor médio de $\mathrm{pH}$ variou de 4,72 $\pm 0,11$ a $4,51 \pm 0,19$, para 22 horas de fermentação, e de 4,45 $\pm 0,07$ a 4,34 0,05 , para 24 horas de fermentação.

Estes valores foram satisfatórios, pois o $\mathrm{pH}$ inicial deve estar entre 4,5 e 5,0, podendo chegar a 4,0, durante a vida-de-prateleira do produto, sem ter um efeito prejudicial sobre a viabilidade das bactérias probióticas (Lee \& Salmien, 1995).

A análise conjunta dos resultados demonstrou que a variação da acidez e do $\mathrm{pH}$ foi influenciada principalmente pelas variáveis tempo e temperatura de estocagem (Tabela 1).

A viabilidade de $L$. casei esteve acima de $10^{6} \mathrm{UFC} \mathrm{mL}^{-1}$ durante os 30 dias de armazenamento a 5 e $10^{\circ} \mathrm{C}$, requisito exigido para considerar o leite fermentado como um produto probiótico. Os valores médios (log UFC $\mathrm{mL}^{-1}$ ) variaram no tempo inicial de $9,62 \pm 0,55$ a $9,37 \pm 0,17$, para 22 horas, e de $9,97 \pm 0,97$ a $9,84 \pm 0,62$, para 24 horas. Os valores finais médios ( $\log$ UFC $\mathrm{mL}^{-1}$ ) variaram de $8,99 \pm 0,35$ a $8,37 \pm 0,18$, para

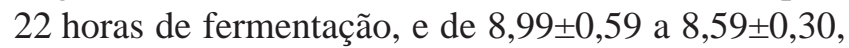
para 24 horas de fermentação.
Na regressão dos dados de viabilidade de $L$. casei, utilizaram-se as variáveis concentração de açúcar, temperatura de estocagem e acidez. No lugar da variável tempo de estocagem, utilizou-se a acidez, pois, como estas variáveis apresentam forte correlação, optou-se pela acidez para identificar se o aumento nesta variável teve influência direta na diminuição do número de L. casei e em que proporção isto ocorreu.

Apenas a acidez influenciou significativamente a viabilidade de $L$. casei no leite fermentado por 22 e 24 horas $(p<0,01)$. De acordo com a equação da reta obtida pela regressão, os valores de $-2,461$, para 22 horas, e de $-2,089$, para 24 horas, representam que uma variação na acidez de $1 \%$ levaria à diminuição da viabilidade de $L$. casei em 2,46 log UFC $\mathrm{mL}^{-1}$ no leite fermentado por 22 horas, e 2,08 $\log$ UFC $\mathrm{mL}^{-1}$ no fermentado por 24 horas. Portanto, a regressão dos dados obtidos a partir do leite fermentado por 24 horas apresentou melhores resultados em relação à viabilidade de L casei (Tabela 1).

A concentração de açúcar não influenciou a viabilidade de $L$. casei, pois a quantidade de lactose presente no leite é suficiente para o metabolismo destes micror-

Tabela 1. Equações da reta e resultados obtidos por regressão linear múltipla para as variáveis acidez, pH e viabilidade de L. casei, nos leites fermentados por 22 e 24 horas $^{(1)}$.

\begin{tabular}{|c|c|c|}
\hline Amostra & Leite fermentado por 22 horas & Leite fermentado por 24 horas \\
\hline & & Acidez \\
\hline $\mathrm{R}^{2}$ & $0,874^{* *}$ & $0,928^{* *}$ \\
\hline Teste F & $207,150^{* *}$ & $384,580^{* *}$ \\
\hline \multicolumn{3}{|l|}{ Teste $\mathrm{t}$} \\
\hline Tempo de estocagem & $24,085^{* *}$ & $33,415^{* *}$ \\
\hline Temperatura de estocagem & $5,198^{* *}$ & $5,769^{* *}$ \\
\hline Concentração de açúcar & $2,513^{*}$ & $1,974^{\mathrm{ns}}$ \\
\hline Equação da reta & $\mathrm{Y}=0,463+0,010 \mathrm{t}+0,011 \mathrm{~T}+0,007 \mathrm{~A}+\varepsilon$ & $\mathrm{Y}=0,544+0,017 \mathrm{t}+0,012 \mathrm{~T}+0,006 \mathrm{~A}+\varepsilon$ \\
\hline & & $\mathrm{pH}$ \\
\hline $\mathrm{R}^{2}$ & $0,776^{* *}$ & $0,869^{* *}$ \\
\hline Teste F & $207,150^{* *}$ & $384,580^{* *}$ \\
\hline \multicolumn{3}{|l|}{ Teste $\mathrm{t}$} \\
\hline Tempo de estocagem & $-17,095^{* *}$ & $23,939^{* *}$ \\
\hline Temperatura de estocagem & $-4,166^{* *}$ & $3,780^{* *}$ \\
\hline Concentração de açúcar & $-1,797^{\mathrm{ns}}$ & $2,887^{* *}$ \\
\hline \multirow[t]{2}{*}{ Equação da reta } & $\mathrm{Y}=5,514-0,020 \mathrm{t}-0,020 \mathrm{~T}-0,013 \mathrm{~A}+\varepsilon$ & $\mathrm{Y}=5,163-0,018 \mathrm{t}-0,012 \mathrm{~T}-0,014 \mathrm{~A}+\varepsilon$ \\
\hline & \multicolumn{2}{|c|}{ Viabilidade de L.casei } \\
\hline $\mathrm{R}^{2}$ & $0,471^{* *}$ & $0,464^{* *}$ \\
\hline Teste F & $207,150^{* *}$ & $384,580^{* *}$ \\
\hline \multicolumn{3}{|l|}{ Teste $t$} \\
\hline Acidez & $-7,002^{* *}$ & $33,415^{* *}$ \\
\hline Temperatura de estocagem & $0,079^{\text {ns }}$ & $5,769^{\mathrm{ns}}$ \\
\hline Concentração de açúcar & $0,960^{\mathrm{ns}}$ & $1,974^{\text {ns }}$ \\
\hline Equação da reta & $\mathrm{Y}=10,625+0,001 \mathrm{~T}+0,028 \mathrm{~A}-2,461 \mathrm{a}+\varepsilon$ & $\mathrm{Y}=10,744-0,001 \mathrm{~T}+0,045 \mathrm{~A}-2,089 \mathrm{a}+\varepsilon$ \\
\hline
\end{tabular}

${ }^{(1)} \mathrm{R}^{2}$ : coeficiente de determinação; Y: acidez, pH ou viabilidade; t: tempo de estocagem; T: temperatura de estocagem; A: concentração de açúcar;

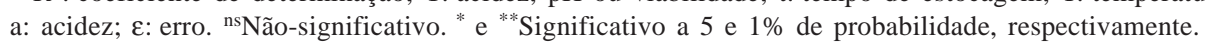


ganismos. Desta forma, a adição de sacarose tem apenas a finalidade de proporcionar características sensoriais adequadas ao paladar do consumidor brasileiro, que prefere produtos doces.

A manutenção da viabilidade de $L$. casei à temperatura de $10^{\circ} \mathrm{C}$ é um resultado importante, pois existem problemas na continuidade da cadeia de frio durante a distribuição e venda de laticínios e no atendimento dos critérios de temperatura adequados para o armazenamento desses produtos. A temperatura de balcões refrigerados geralmente fica próxima de $10^{\circ} \mathrm{C}$.

Os resultados foram satisfatórios, pois a variação da acidez e do $\mathrm{pH}$ observados durante a estocagem do produto não foi prejudicial à viabilidade das bactérias probióticas. Vinderola et al. (2002) verificaram que não ocorreu diminuição significativa do número de células viáveis de $L$. casei (decréscimo na contagem menor que $0,4 \mathrm{log}$ ), durante quatro semanas de estocagem refrigerada, em leite de vaca fermentado com pH 4,0.

Ao se considerar que os parâmetros de acidez, $\mathrm{pH}$ e viabilidade de $L$. casei iniciais foram adequados tanto para o leite fermentado por 22 horas quanto por 24 horas, e que estes foram mantidos dentro de limites aceitáveis depois da estocagem por 30 dias, foi possível inferir que, observadas as condições experimentais, o produto pode ser elaborado com concentrações de açúcar entre 10 e $14 \%$ e estocado entre 5 e $10^{\circ} \mathrm{C}$ por até 30 dias, sem que ocorra aumento da acidez e do pH acima do aceitável, ou redução drástica do número de microrganismos viáveis.

\section{Conclusões}

1. O leite de búfala fermentado pode ser elaborado por fermentação durante 22 a 24 horas, com concentração de açúcar variando entre 10 e $14 \%$, e estocado entre 5 e $10^{\circ} \mathrm{C}$, durante 30 dias.

2. O tempo de fermentação de 24 horas é o mais adequado, por apresentar maior viabilidade de Lactobacillus casei.

3. A variação do pH e da acidez é influenciada principalmente pelo tempo de estocagem e, em menor proporção, pela temperatura de estocagem.

4. A variação da viabilidade de $L$. casei é influenciada exclusivamente pela acidez.

\section{Referências}

ALM, L. The therapeutic effects of various cultures - an overview. In: ROBINSON, R.K. (Ed.). Therapeutic properties of fermented milks. London: Elsevier, 1991. p.45-64.
ASSOCIATION OF OFFICIAL ANALYTICAL CHEMISTS. Official methods of analysis of the AOAC International. $14^{\text {th }}$ ed. [S. 1.], 1984. 1141p.

BENEVIDES, C.M. de J. Leite de búfala - qualidades tecnológicas. Higiene Alimentar, v.13, p.18-21, 1998.

BRASIL. Ministério da Agricultura, Pecuária e Abastecimento. Resolução n⿳o 05, de 13 de novembro de 2000. Padrão de identidade e qualidade de leites fermentados. Brasília, 2000.

FOOD AND AGRICULTURE ORGANIZATION (Roma, Itália). O búfalo. Brasília: Ministério da Agricultura; São Paulo: Associação Brasileira dos Criadores de Búfalo, 1991. 320p. (Produção animal e saúde, 4).

GOMES, A.M.P.; MALCATA, F.X. Bifidobacterium spp. and Lactobacillus acidophilus: biological, biochemical, technological and therapeutical properties relevant for use as probiotics. Trends in Food Science and Technology, v.10, p.139-157, 1999.

HELLER, K.J. Probiotic bacteria in fermented foods: product characteristics and starter organisms. American Journal of Clinical Nutrition, v.73, p.374-379, 2001.

HÜHN, S.; LOURENÇO JUNIOR, J.B.; MOURA CARVALHO, L.O.D.; NASCIMENTO, C.N.B.; VIEIRA, L.C. Aproveitamento do leite de búfala em produtos derivados. In: SIMPÓSIO DO TRÓPICO ÚMIDO, 1., 1984, Belém. Anais. Belém: EmbrapaCPATU, 1986. v.5, p.265-269. (Embrapa-CPATU. Documentos, 36).

HÜHN, S.; LOURENÇO JUNIOR, J.B.; MOURA CARVALHO, L.O.D.; NASCIMENTO, C.N.B.; VIEIRA, L.C. Características, peculiaridades e tecnologia do leite de búfala. Belém: EmbrapaCPATU, 1991. 51p. (Embrapa-CPATU. Documentos, 57).

LEE, Y.K.; SALMINEN, S. The coming of age of probiotics. Trends in Food Science and Technology, v.6, p.241-245, 1995.

NASCIMENTO, C.; CARVALHO, L.O.M. Criação de búfalos: alimentação, manejo, melhoramento e instalações. Brasília: EmbrapaSPI, 1993. 403p.

PIARD, J.-C.; HAUTEFORT, I.; FISCHETTI, V.A.; EHRLICH, S.D.; FONS, M.; GRUSS, A. Cell wall anchoring of the Streptococcus pyogenes M6 protein in various lactic acid bacteria. Journal of Bacteriology, v.179, p.3068-3072, 1997.

SAAVEDRA, J.M. Agentes probióticos: aplicações clínicas em lactentes e crianças. In: TRABULSI, L.R.; CHIFFRIN, E.J.; SAMPAIO, M.M.S.; SAAVEDRA, J.M. Temas de pediatria Nestlé. São Paulo: Nestlé, 2000. 36p. (Temas de pediatria Nestlé. Número especial).

SCHREZENMEIR, J.; VRESE, M. de. Probiotics, prebiotics and symbiotics - approaching a definition. American Journal of Clinical Nutrition, v.73, p.361-364, 2001.

STATSOFT. Statistica $\mathbf{5 . 1}$ for Windows. Tulsa, OK, 1998.

TAMINE, A.Y.; MARSHALL, V.M.E.; ROBINSON, R.K. Microbiological and technological aspects of milk fermented by bifidobacteria. Journal of Dairy Research, v.62, p.151-187, 1995. 
TRABULSI, L.R.; SAMPAIO, M.M.S.C. Probióticos, prebióticos e simbióticos. In: TRABULSI, L.R.; CARNEIRO-SAMPAIO, M.M.S. Os probióticos e a saúde infantil. São Paulo: Nestlé, 2000. 15p. (Temas de pediatria Nestlé, 3).

VANDERZANT, C.; SPLITTSTOESSER, D.F. Compendium of methods for the microbiological examination of food. Washington: American Public Health Association, 1984. $914 p$.
VINDEROLA, C.G.; COSTA, G.A.; REGENHARDT, S.; REINHEIMER, J.A. Influence of compounds associated with fermented dairy products on the growth of lactic acid starter and probiotic bacteria. International Dairy Journal, v.12, p.579-589, 2002.

VRESE, M. de; STEGELMANN, A.; RICHTER, B.; FENSELAU, S.; LAUE, C.; SCHREZENMEIR, J. Probiotics: compensation for lactase insufficiency. American Journal of Clinical Nutrition, v.73, p.421-426, 2001.

Recebido em 26 de janeiro de 2005 e aprovado em 8 de julho de 2005 